\title{
OP76
}

\section{COMBINED OUT OF RANGE AND IN BAND STRAY LIGHT CORRECTION FOR ARRAY SPECTRORADIOMETERS}

\author{
Ralf Zuber et al.
}

DOI 10.25039/x46.2019.OP76

from

CIE x046:2019

\author{
Proceedings \\ of the \\ 29th CIE SESSION \\ Washington D.C., USA, June 14 - 22, 2019 \\ (DOI 10.25039/x46.2019)
}

The paper has been presented at the 29th CIE Session, Washington D.C., USA, June 14-22, 2019. It has not been peer-reviewed by CIE.

(C) CIE 2019

All rights reserved. Unless otherwise specified, no part of this publication may be reproduced or utilized in any form or by any means, electronic or mechanical, including photocopying and microfilm, without permission in writing from CIE Central Bureau at the address below. Any mention of organizations or products does not imply endorsement by the CIE.

This paper is made available open access for individual use. However, in all other cases all rights are reserved unless explicit permission is sought from and given by the CIE.

CIE Central Bureau

Babenbergerstrasse 9

A-1010 Vienna

Austria

Tel.: +4317143187

e-mail: ciecb@cie.co.at

www.cie.co.at 


\title{
COMBINED OUT OF RANGE AND IN BAND STRAY LIGHT CORRECTION FOR ARRAY SPECTRORADIOMETERS
}

\author{
Zuber, R. ${ }^{1}$, Ribnitzky, M. ${ }^{1}$ \\ ${ }^{1}$ Gigahertz-Optik GmbH, Türkenfeld, GERMANY \\ r.zuber@gigahertz-optik.de
}

DOI $10.25039 / \times 46.2019 .0 P 76$

\begin{abstract}
Insufficient stray light rejection of array spectroradiometers, in especially the UV spectral range, limits the application of these devices. One important example would be UV hazard measurements. This study shows that a combination of different stray light corrections methods can improve the stray light reduction performance of UV array spectroradiometers significantly, to meet these requirements. The ACGIH E eff (identical ICNIRP) values measured with an uncorrected array spectroradiometer showed expected large deviations of $73 \%$ for a sunbed tanning lamp and $105 \%$ for a halogen lamp, relative to a double monochromator reference.

With the applied combined Out-of-Range and In-Band stray light correction method, these measurements were within $3 \%$ of the reference double monochromator based system.

Furthermore, the measurements showed a detection limit of $2 \mathrm{E}-5 \mathrm{~W} / \mathrm{m}^{2} / \mathrm{nm}$ for the double monochromator and comparable $3 \mathrm{E}-5 \mathrm{~W} / \mathrm{m}^{2} / \mathrm{nm}$ for the stray light corrected array spectroradiometer. This was in contrast to $5 \mathrm{E}-4 \mathrm{~W} / \mathrm{m}^{2} / \mathrm{nm}$ for the uncorrected array spectroradiometer. The results suggest that photobiological safety measurements according to IEC / DIN EN 62471 are possible with the applied combined stray light correction method for the used spectroradiometer.
\end{abstract}

Keywords: Spectroradiometer, Stray light reduction, UV hazard

\section{Introduction}

Typically, insufficient stray light rejection of array spectroradiometers in the blue and especially in the UV spectral range limits the application of these devices in this spectral region (Egli et al., 2016). One such important example would be UV hazard measurements. The measurements required to determine the American Conference of Governmental Industrial Hygienists (ACGIH) corneal hazard of broadband ultraviolet (UV) sources make particularly high demands on the suppression of stray light. The same applies to photobiological safety within IEC/DIN EN 62471 or ICNIRP (International Commission on Nonlonizing Radiation Protection) UV measurements (ICNIRP, 1995). Hence, the accepted and recommended technology/devices are double monochromator based systems (IEC/DIN EN 62471).

This study shows that a combination of stray light suppression by different correction methods can improve the stray light reduction performance of UV array spectroradiometers significantly to meet these requirements.

\section{Methods}

In an array spectroradiometer two different types of internal stray light can be distinguished by its origin. The so called Out-of-Range (OoR) stray light is generated by a signal outside the spectral range of the spectroradiometer; stray light originating from within the spectral range of the spectroradiometer is referred as In-Band (IB) stray light (ISO/CIE, 1984, CIE, 2018). The OoR stray light can be measured and corrected by using edge filters for instance (Shaw and Goodman, 2008, Nevas, 2015). However, these methods are not able to correct for IB stray light. The IB stray light can be corrected by using established stray light matrix correction (SLMC) methods (Zong et al., 2006, Nevas et al., 2012). The presented study uses a combination of both methods in order to achieve significantly improved performance; especially for dedicated UV array spectroradiometers which are silicon detector based and therefore, depending on the light source, may have significant OoR and IB stray light. 
An intercomparison of a corrected and an uncorrected array spectroradiometer and a double monochromator reference has been performed by measuring different light sources (tungsten, xenon, sunbed tanning lamp, light emitting diode (LED)).

\section{Instrument design and characterisation}

The BTS2048-UV-S series array spectroradiometers developed and manufactured by Gigahertz-Optik are based on the well-known Czerny-Turner (Shafer et al., 1964) spectrometer design. The spectrometer uses a temperature controlled back-thinned CCD detector with 2048 pixels and an electronic shutter integrated in a compact optical bench with 16 bit analogue digital converter (ADC) resolution. To enable stray light corrected measurements, a miniaturised filter wheel with up to six different optical filters is integrated in the optical path between the entrance optic and spectrometer unit. Integration times from $2 \mu \mathrm{s}$ up to $60 \mathrm{~s}$ provide a high dynamic range in the spectral range from $200 \mathrm{~nm}$ to $430 \mathrm{~nm}$ (Zuber et al., 2018b). Various device versions with different spectral range and input optics exist. The BTS2048-UV-S with OoR stray light correction already applied, is introduced and characterized for instance with respect to linearity, optical bandwidth, cosine response and wavelength accuracy in Zuber et al. (2018b) and Zuber et al. (2018a). A measurement uncertainty evaluation of this device is presented for direct irradiance measurements, calibrated with a low standard uncertainty calibration source of PTB, in Vaskuri et al. (2018). In the following Figure 1, a schematic diagram is shown. In Table 1 the uncertainty budget from Vaskuri et al. (2018) is presented.
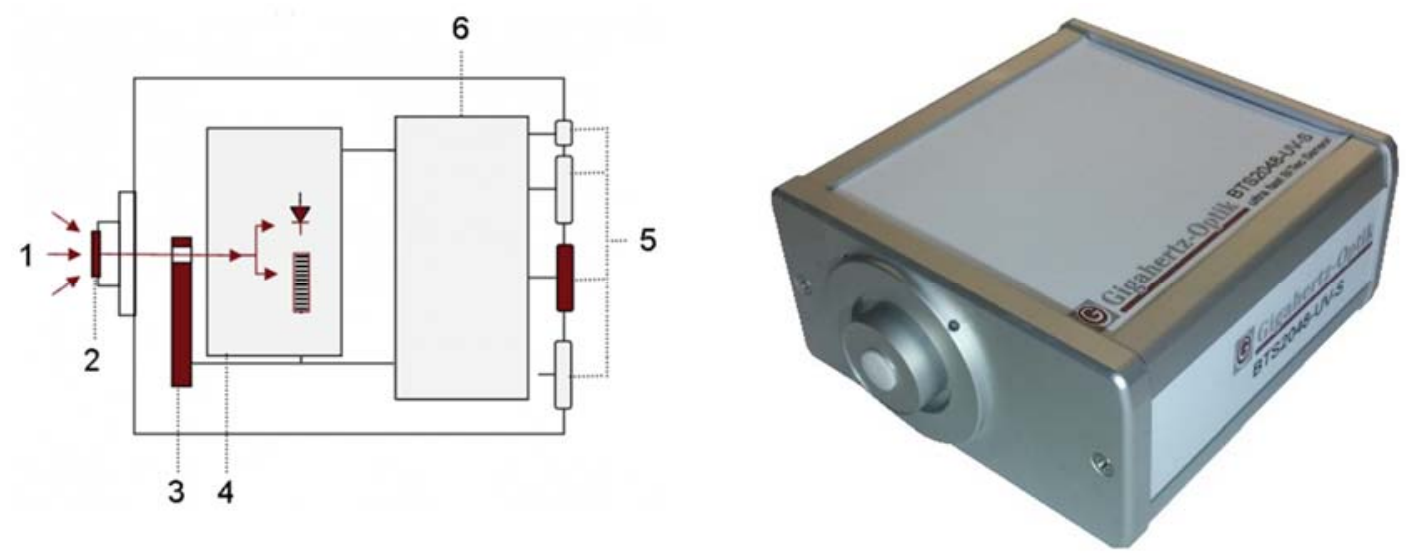

Figure 1 - Schematic setup of the BTS2048-UV-S and photo of the instrument. 1) Incoming optical radiation 2) Direct entrance port with cosine diffuser 3) Filter wheel 4) BiTec sensor system 5) Electrical connectors 6) Microprocessor for data processing and communication.

Table 1 - Measurement uncertainties for direct spectral irradiance measurement

\begin{tabular}{|l|l|}
\hline Uncertainty component & Standard uncertainty / \% \\
\hline Radiometric calibration & 0.8 \\
\hline Lamp stability & 0.2 \\
\hline Non-linearity and stray light & 0.4 \\
\hline Stability & 0.8 \\
\hline Temperature dependency & 0.1 \\
\hline Measurement noise & 0.2 \\
\hline Wavelength shift & 0.1 \\
\hline Combined uncertainty $(\mathrm{k}=1)$ & 1.24 \\
\hline Expanded measurement uncertainty $(\mathrm{k}=2.5)$ & 2.5 \\
\hline
\end{tabular}


In this study based on this device the stray light reduction was improved further. Therefore, as stated in chapter 2, a combination of the OoR stray light correction with an edge filter and an IR stray light correction according to Zong et al. (2006) was applied.

\section{Measurement data / intercomparison}

In the following sub-chapters measurements of tungsten, xenon, sunbed tanning lamp and light emitting diode (LED) sources are compared to a double monochromator measurement system, which fulfils the IEC/DIN EN 62471 specifications. In order to illustrate the performance of the combined stray light correction, the uncorrected data (no OoR and IB correction applied) is also presented.

\subsection{Halogen lamp}

In Figure 2 a $250 \mathrm{~W}$ halogen lamp measurement at $500 \mathrm{~mm}$ distance is illustrated with logarithmic scale to show the differences in stray light performance.

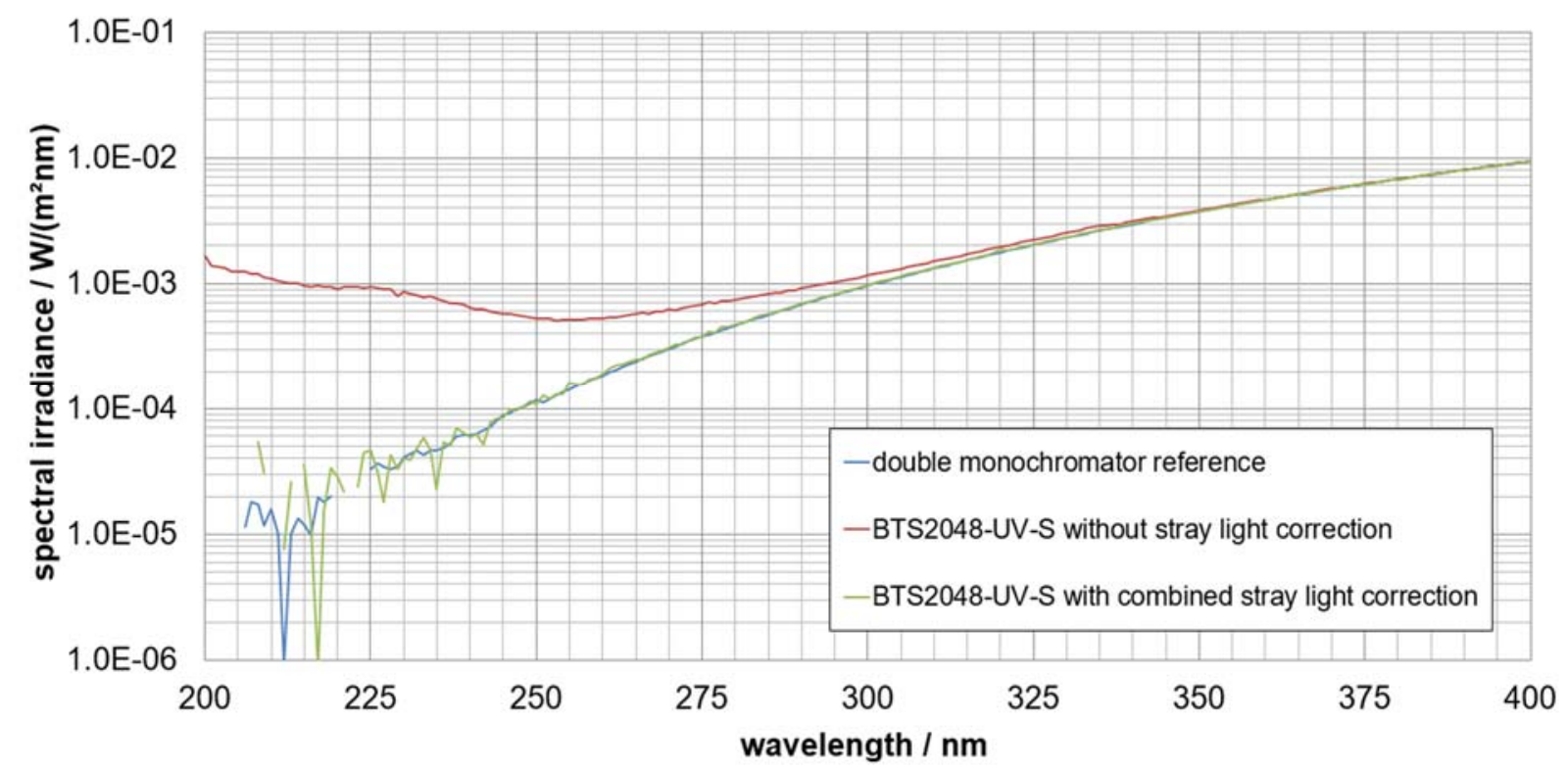

Figure 2 - Logarithmic plot of an intercomparison measurement of a $250 \mathrm{~W}$ halogen lamp at $500 \mathrm{~mm}$ distance from a double monochromator reference and the BTS2048-UV-S with and without correction.

\subsection{Sunbed tanning lamp}

In Figure 3 a $4 \times 15 \mathrm{~W}$ sunbed tanning lamp measurement at $150 \mathrm{~mm}$ distance is illustrated with logarithmic scale to show the differences in stray light performance. 


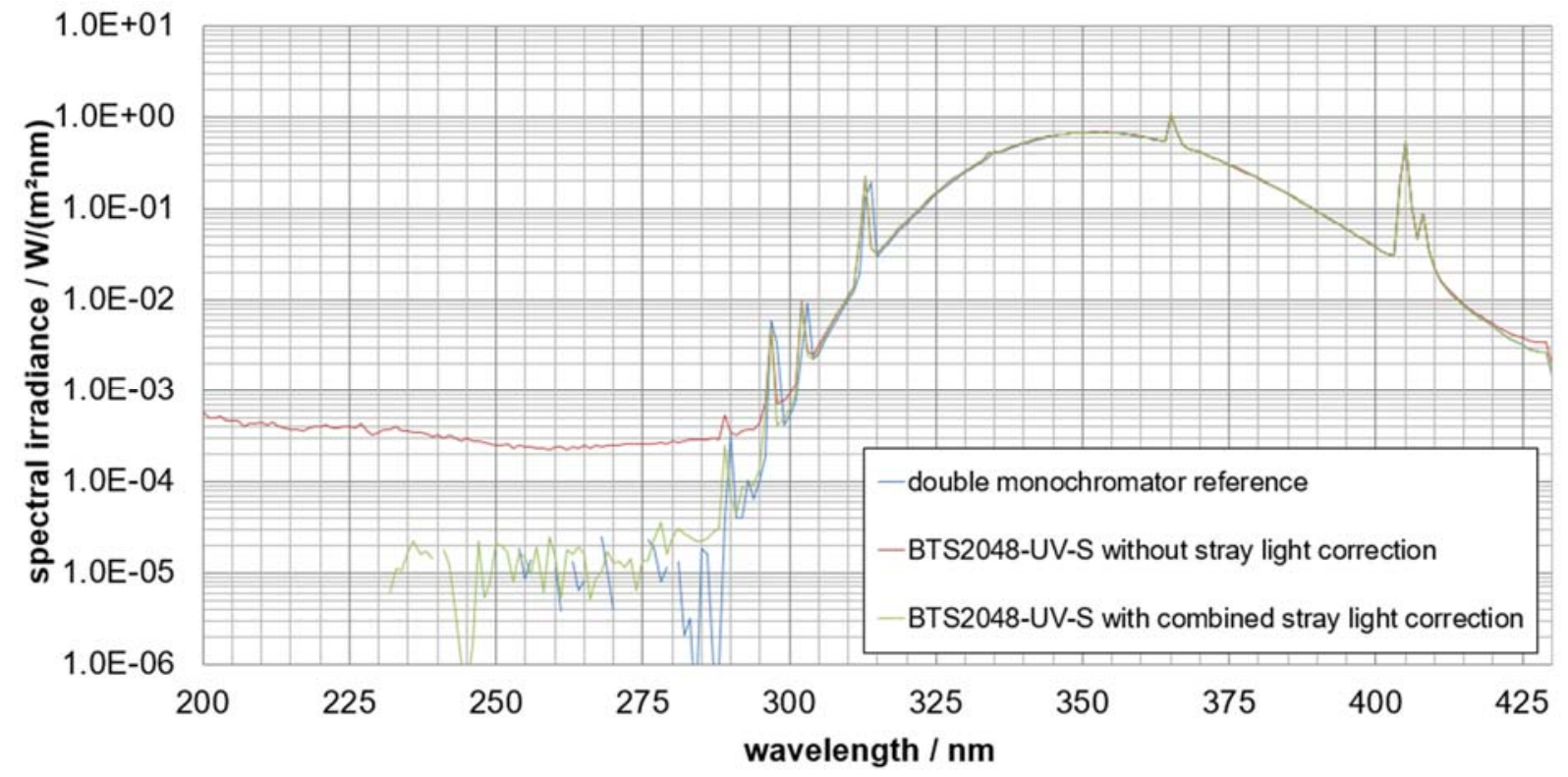

Figure 3 - Logarithmic plot of an intercomparison measurement of a $4 \times 15 \mathrm{~W}$ sunbed tanning lamp at $150 \mathrm{~mm}$ distance from a double monochromator reference and the BTS2048-UV-S with and without correction.

\subsection{Xenon lamp}

In Figure 4 a $450 \mathrm{~W}$ xenon lamp measurement at $180 \mathrm{~mm}$ distance is illustrated with logarithmic scale to show the differences in stray light performance.

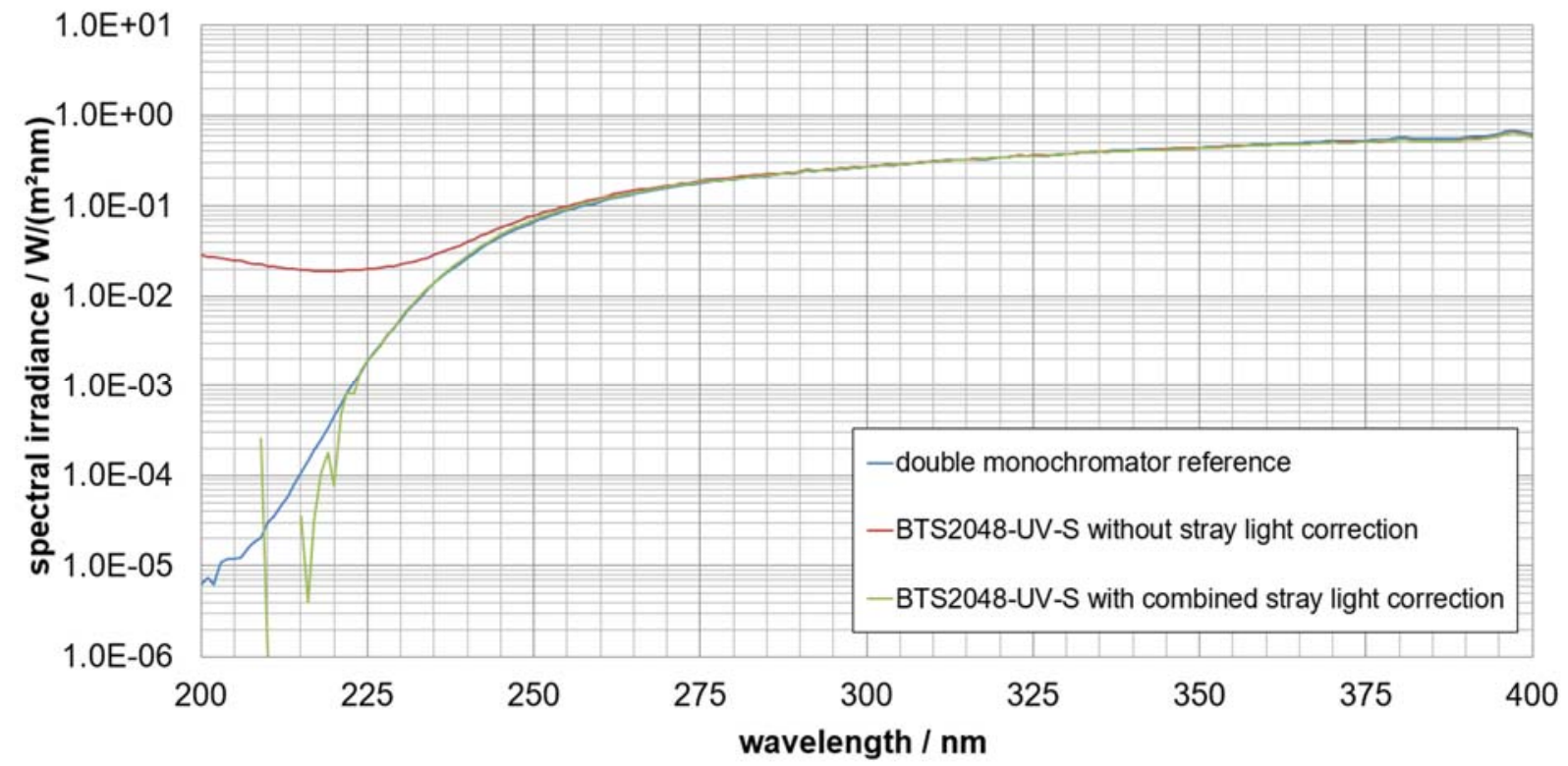

Figure 4 - Logarithmic plot of an intercomparison measurement of a $450 \mathrm{~W}$ halogen lamp at $180 \mathrm{~mm}$ distance from a double monochromator reference and the BTS2048-UV-S with and without correction.

\subsection{Light emitting diode (LED)}

In Figure 5 a $365 \mathrm{~nm}$ LED measurement at $500 \mathrm{~mm}$ distance is illustrated with logarithmic scale to show the differences in stray light performance. 


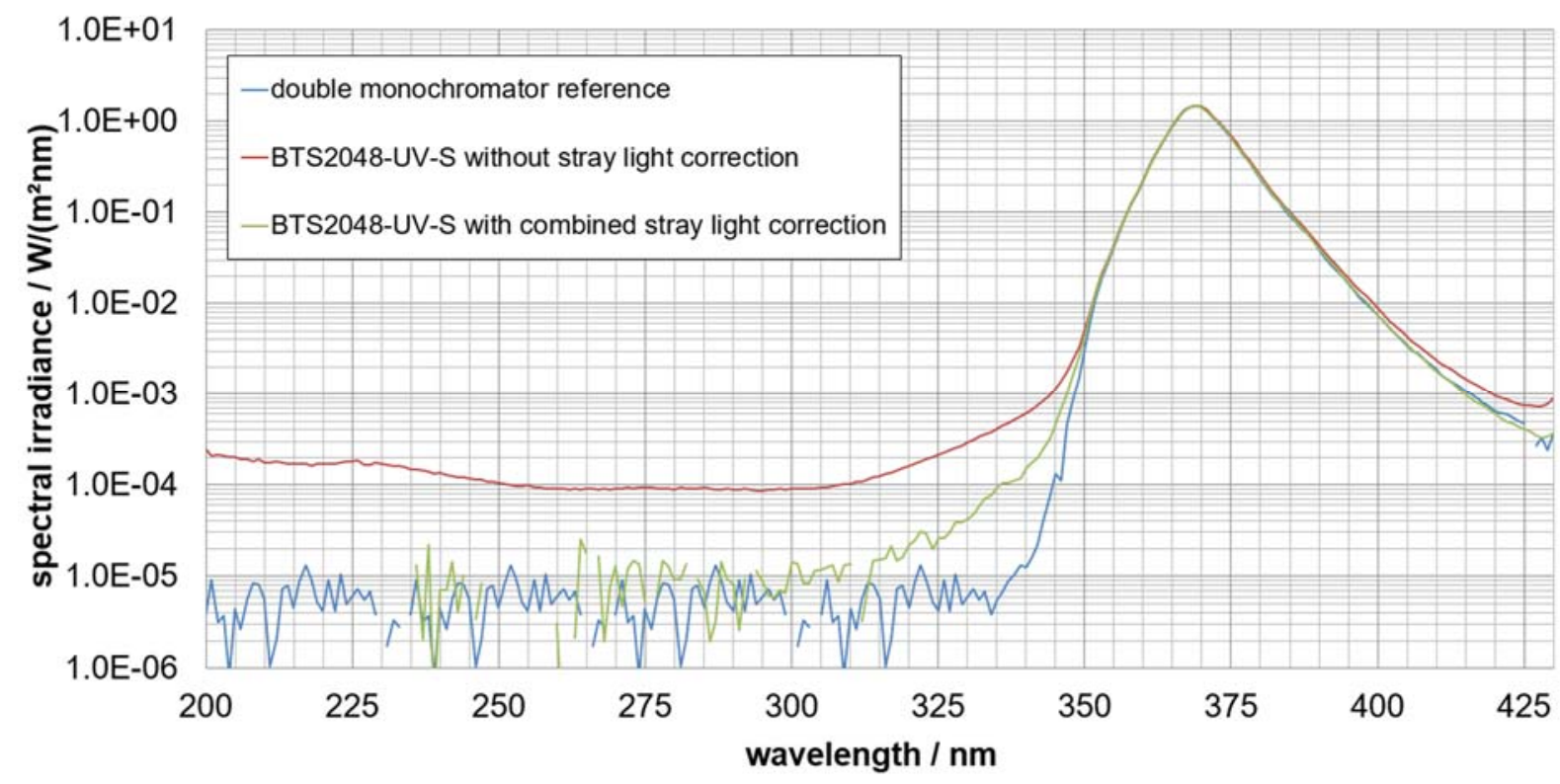

Figure 5 - Logarithmic plot of an intercomparison measurement of a $365 \mathrm{~nm}$ LED at $500 \mathrm{~mm}$ distance from a double monochromator reference and the BTS2048-UV-S with and without correction.

In Table 2 the deviation of ACGIH $E_{\text {eff }}$ and the detection limit of the different array spectroradiometer measurements are presented.

Table 2 - Intercomparison

\begin{tabular}{|c|l|c|c|c|c|}
\hline \multicolumn{2}{|c|}{} & Halogen lamp & $\begin{array}{c}\text { Sunbed tanning } \\
\text { lamp }\end{array}$ & $\begin{array}{c}\text { Xenon } \\
\text { lamp }\end{array}$ & $\begin{array}{c}365 \mathrm{~nm} \\
\text { LED }\end{array}$ \\
\hline $\begin{array}{c}\text { Deviation } \\
\text { Eeff }_{\text {eff }}\end{array}$ & without SLC & $105 \%$ & $74 \%$ & $6.7 \%$ & $7.6 \%$ \\
\cline { 2 - 6 } & combined SLC & $1.5 \%$ & $-2.5 \%$ & $2.1 \%$ & $0.4 \%$ \\
\hline $\begin{array}{c}\text { Detection } \\
\text { limit }\end{array}$ & without SLC & $1 \mathrm{E}-3$ & $2 \mathrm{E}-4$ & $2 \mathrm{E}-2$ & $1 \mathrm{E}-4$ \\
\cline { 2 - 6 } & combined SLC & $2 \mathrm{E}-5$ & $1 \mathrm{E}-5$ & $3 \mathrm{E}-5$ & $1 \mathrm{E}-5$ \\
\hline
\end{tabular}

Note: For the evaluation of the $365 \mathrm{~nm} L E D$ values, only the spectral range from $300 \mathrm{~nm}$ to $430 \mathrm{~nm}$ was used.

\section{Discussion and conclusion}

The ACGIH $E_{\text {eff }}\left(E_{\text {eff }}=\right.$ effective irradiance; weighted; identical ICNIRP weighted or IEC/DIN EN 62471) values measured with the uncorrected array spectroradiometer showed expected large deviations of $73 \%$ for the sunbed tanning lamp and $105 \%$ for the halogen lamp relative to the double monochromator. For a xenon lamp and a $365 \mathrm{~nm}$ LED the deviation is below $10 \%$. These results show why double monochromators are the recommended devices for this kind of measurement.

However, with the use of the introduced combined stray light correction methods, all $E_{\text {eff }}$ values measured with the array spectroradiometer (independent of the light source measured) were within $3 \%$ of the double monochromator reference. These comparable results suggest that for the used device with the introduced combined stray light correction method, UV hazard evaluations according to ACGIH/ICNIRP or IEC/DIN EN 62471 (2006) are possible.

The results showed that the most critical light source tested in terms of stray light was the xenon lamp with a detection limit of $3 \mathrm{E}-5$. The uncorrected measurement reached only a level of $2 \mathrm{E}-2$. For this specific light source, an improvement of three orders of magnitude was achieved. The least critical light source was the LED with a detection limit of $1 \mathrm{E}-5$ for the corrected measurement and 1E-4 for the uncorrected measurement. These different stray light levels can be explained by the different relative spectral distributions of the light sources. The xenon lamp produces more IB and OoR stray light compared to the $365 \mathrm{~nm}$ LED. 


\section{References}

62471, I. D. E. 2006. IEC/DIN EN 62471 Photobiological safety of lamps and lamp systems.

CIE 2018. TC 2-51: Calibration, Characterisation and Use of Array Spectroradiometers.

EGLI, L., GRÖBNER, J., HÜLSEN, G., BACHMANN, L., BLUMTHALER, M., DUBARD, J., KHAZOVA, M., KIFT, R., HOOGENDIJK, K., SERRANO, A., SMEDLEY, A. \& VILAPLANA, J. M. 2016. Quality assessment of solar UV irradiance measured with array spectroradiometers. Atmos. Meas. Tech., 9, 1553-1567.

ICNIRP 1995. Global Solar UV Index. A joint recommendation of the World Health Organization, the World Meteorological Organization, the United Nations Environment Programme, and the International Commission on Non-lonizing Radiation Protection. International Commission on Non-Ionizing Radiation Protection, Oberschleißheim.

ISO/CIE 1984. The spectroradiometric measurement of light sources. CIE 63.

NEVAS, S. 2015. CIE Tutorial and Practical Workshop on CIE S 025 - Spectroradiometry.

NEVAS, S., WÜBBELER, G., SPERLING, A., ELSTER, C. \& TEUBER, A. 2012. Simultaneous correction of bandpass and stray-light effects in array spectroradiometer data. Metrologia, 49 , S43.

SHAFER, A. B., MEGILL, L. R. \& DROPPLEMAN, L. 1964. Optimization of the Czerny-Turner Spectrometer*. Journal of the Optical Society of America, 54, 879-887.

SHAW, M. \& GOODMAN, T. 2008. Array-based goniospectroradiometer for measurement of spectral radiant intensity and spectral total flux of light sources. Applied Optics, 47, 26372647.

VASKURI, A., KÄRHÄ, P., EGLI, L., GRÖBNER, J. \& IKONEN, E. 2018. Uncertainty analysis of total ozone derived from direct solar irradiance spectra in the presence of unknown spectral deviations. Atmos. Meas. Tech., 11, 3595-3610.

ZONG, Y., BROWN, S. W., JOHNSON, B. C., LYKKE, K. R. \& OHNO, Y. 2006. Simple spectral stray light correction method for array spectroradiometers. Applied Optics, 45, 1111-1119.

ZUBER, R., RIBNITZKY, M., TOBAR, M., LANGE, K., KUTSCHER, D., SCHREMPF, M., NIEDZWIEDZ, A. \& SECKMEYER, G. 2018a. Global spectral irradiance array spectroradiometer validation according to WMO. Measurement Science and Technology.

ZUBER, R., SPERFELD, P., RIECHELMANN, S., NEVAS, S., SILDOJA, M. \& SECKMEYER, G. 2018b. Adaption of an array spectroradiometer for total ozone column retrieval using direct solar irradiance measurements in the UV spectral range. Atmos. Meas. Tech., 11, 2477-2484, https://doi.org/10.5194/amt-11-2477-2018, 2018, 1-12. 